This is the version of the article accepted for publication in LANGUAGE AND SOCIOCULTURAL THEORY published by Equinox Publishing: https://doi.org/10.1558/lst.34514

Accepted version downloaded from SOAS Research Online: http://eprints.soas.ac.uk/25615

\title{
Pair-work dynamics: Stronger learners' languaging engagement and learning outcomes for the Japanese polysemous particles ni/de
}

Authors: Kyoko Masuda, Noriko Iwasaki

Abstract

Adopting microgenetic analysis of languaging (Swain, 2006) in pair-work, this study aims to advance our understanding of learners' developmental processes for the complex concepts of Japanese particles ni/de. Two pairs whose learning outcomes differed were chosen, and their languaging was examined, focusing on "stronger" learners, the peers who showed more targetlike knowledge of particles on fill-in-the-blank pre-test than their partners. Both interaction patterns and quality of engagement appeared to have facilitated their conceptual internalisation for the Japanese particles nilde. A stronger learner in one of the pairs demonstrated reciprocal elaborate engagement in a collaborative pattern, and greatly improved his understanding and retained it longer-term. In contrast, a stronger learner in the other pair, who demonstrated nonreciprocal limited engagement in dominant-passive interaction, showed no development over time. Follow-up interviews revealed these peers' differing attitudes toward pair-work, which were likely conducive to their engagement in pair-work and L2 learning outcome.

Keywords: languaging, microgenesis, collaborative orientation, students' perceptions and attitudes, Japanese particles ni/de

\section{INTRODUCTION}

Second/foreign language (L2) instruction often utilizes pair-work to facilitate interaction and language learning (Philp, Adams, and Iwashita, 2014; Sato and Ballinger, 2016); however, this does not always create equivalent learning opportunities for all learners.

Among the important interrelated factors influencing pair-work interaction and learning are collaborative orientation (Ohta, 2001; Storch, 1999, 2001, 2002, 2013; Swain and Lapkin, 1998, 2002), the quality/degrees of engagement (McDonough, 2004; Storch, 2008; Storch and Aldosari, 2012), learners' L2 proficiencies (Ohta, 1995, 2001; Leeser, 2004; Storch and Aldosari, 2012; Watanabe and Swain, 2007), and perceptions/attitudes (Kim and McDonough, 2008; Storch, 2004, 2005; Watanabe and Swain, 2008).

A key feature of pair-work interaction is collaborative dialogue - 'dialogue in which speakers are engaged in problem solving and knowledge building' (Swain, 2000: 102). Through collaborative dialogue, learners become aware of linguistic problems, organize their output, and co-construct their linguistic knowledge. Swain (2006) argues for the significance of verbalization, or 'languaging', whether talking to others or oneself. She defined languaging as a '...process of making meaning and shaping knowledge and experience through language' (p. 98). This on-going moment-to-moment process of language learning through languaging can be captured in microgenesis, a methodological construct of Sociocultural Theory (SCT). Microgenesis, the term coined by Wertsch (1985), provides a kind of '...analysis that returns to the source and reconstructs all the points in the development of a given structure' (Vygotsky, 1978: 65). 
This is the version of the article accepted for publication in LANGUAGE AND SOCIOCULTURAL THEORY published by Equinox Publishing: https://doi.org/10.1558/lst.34514

Accepted version downloaded from SOAS Research Online: http://eprints.soas.ac.uk/25615

Research has demonstrated that languaging mediates L2 learning of complex grammatical items such as French voice (Swain, Lapkin, Knouzi, Suzuki, and Brooks, 2009) and Spanish modality (Negueruela and Lantolf, 2006). Building upon this research, our study uses microgenetic analysis to examine languaging in pair-work. We focus on the conceptual development of students who showed greater knowledge of the target Japanese particles ni/de than their partners before the pair-work (henceforth 'stronger learners'). The question of how stronger (more proficient) peers benefit from pair-work with weaker peers has been relatively under-explored, and this question can be most aptly answered from a fine-grained qualitative analysis. Thus, we explore the close relationships among stronger learners' level of engagement in languaging, their learning outcomes over time, and their perceptions and attitudes toward pairwork.

\section{BACKGROUND}

\section{Microgenesis in sociocultural theory}

Microgenetic analysis, described by Lantolf (2000: 3) as 'a domain where interest is in the reorganization and development of mediation over a relatively short span of time,' serves both as the method and as the object of study. It allows researchers to capture developmental patterns during the co-creation of knowledge in collaboration from the awareness/consciousness stage to the consolidation of knowledge stage (Ganem-Gutiérrez, 2008). Applied to pair-work, learners' overt learning instances are studied by analyzing a specific interaction and its origin and history of learning.

From the SCT perspective, learning an L2 implies re-mediating mind and cognition by utilizing symbolic tools such as visual aids and verbalization. Verbalization, or languaging, serves as 'an instructional tool for attention focusing, selection analysis, and synthesis and thus is directly connected with internalization and concept formation' (Negueruela and Lantolf, 2006: 86). The learners in our study engaged in languaging to learn the Japanese locative particles ni/de, a concept regarded as difficult for Japanese-as-a-foreign-language (JFL) learners (e.g. Sakoda, 2001; Masuda and Labarca, 2015). Microgenetic analysis reveals not only how particular collaborative activities evolve in a given context but also allows us to glean how learning is achieved through interaction (Lantolf, 2000; Ganem-Gutiérrez, 2008). Hence, it is optimal for understanding JFL learners' conceptual development of the particles in languaging.

\section{Quality of languaging}

Swain et al. (2009) analyzed the quantity and quality of languaging by English-speaking L2 learners of French thinking aloud about French passive/middle/active voice. These researchers examined the learners' languaging units (i.e. units related to conceptual units used in the explanatory texts). They found that learners who used both greater amounts and wider varieties of languaging (e.g. paraphrasing, inference, analysis, and self-assessment) were more successful in accurately identifying passive/middle/active voice and explaining the concept of French voice.

How the quality of languaging affects learning has also been reported elsewhere. Masuda and Labarca (2015), for instance, discovered that there was a positive correlation between a pair's ability to identify and to use Japanese particle functions and their languaging quality (e.g. elaboration on choices of particles' function). Likewise, the effect of quality of written languaging on L2 writing was shown by Suzuki (2016). 
This is the version of the article accepted for publication in LANGUAGE AND SOCIOCULTURAL THEORY published by Equinox Publishing: https://doi.org/10.1558/lst.34514

Accepted version downloaded from SOAS Research Online: http://eprints.soas.ac.uk/25615

Languaging, by learners working in pairs, is examined by analyzing Language Related Episodes (LREs), which are interactions by learners as they reflect upon their language use. Storch (2002), who investigated how ESL learners' LREs in writing, editing, and text reconstruction enhanced learning, categorized LRE interaction patterns into four types: collaborative, expert-novice, dominant-dominant, and dominant-passive. Collaborative interaction (both learners contribute to the task with high engagement) or expert-novice interaction (the expert learner takes the lead and encourages the novice to contribute) led to successful learning outcomes for both learners as gauged by individual performance on a similar editing post-task. In contrast, in dominant-dominant interactions, both learners tried to control the interaction, leading to low engagement and thus less successful outcomes. Likewise, in dominant-passive interactions, where one learner takes control and the other passively contributes, the result is little negotiation and less successful outcomes. Watanabe and Swain (2007: 134) further added an expert/passive pattern (expert learners seek involvement from less proficient peers, and the latter becomes intimidated and is reluctant to participate).

Storch (2008) also examined the quality of learner engagement in LREs, coding engagement either as elaborate, wherein learners deliberated over language items, sought and provided confirmation, explanation and alternatives, or as limited, wherein they simply suggested linguistic items without further deliberation. Only elaborate engagement led to more learning by both learners. According to Storch, elaborate engagement allows both learners to gain a deeper and more systematic understanding by doing hypothesis testing about rule formulation and obtaining timely confirmation.

\section{Learner proficiency and perception}

Learner proficiency and perception of pair-work also significantly influence the dynamics of pair-work. Storch and Aldosari (2012) found that same-proficiency pairs tended to collaborate more and generated more LREs, while different-proficiency pairs exhibited a variety of noncollaborative interaction patterns and fewer LREs. Kim and McDonough (2008) discovered individual differences among intermediate learners when they were paired with intermediate partners and with advanced partners. Some of Kim and McDonough's participants, who were collaborative when paired with intermediate partners, became passive when paired with advanced peers. Other learners who were dominant with intermediate peers showed collaborative interactions with advanced peers. The post-test questionnaire demonstrated that those who became passive felt that the advanced learners tended to dominate, and that those who became collaborative preferred to work with advanced partners. These mixed results suggest that, rather than the partners' proficiency, individual student perception of the pair-work influenced pairwork interaction. These results confirm Storch's (2004) report that perceived shared goals of the tasks were a decisive factor for pair-work dynamics.

Previous work (e.g. Aljaafreh and Lantolf, 1994; Nassaji and Swain, 2000) showed that novice learners in pair-work develop their knowledge of English as an L2 through mediation with an expert in the target language (e.g. a tutor, an expert peer) in the learners' zone of proximal development (ZPD). ${ }^{1}$ Ohta $(1995,2001)$ also revealed that an expert peer progressed when interacting with a novice peer When working with a novice peer, an expert peer refines her own language use while playing with the target form until she can use it with fluency. Watanabe and Swain (2007) argued that higher proficiency collaborative learners achieved higher post-test scores when working with lower rather than higher proficiency partners, because they had more opportunities to provide assistance when working with novice partners. Similarly, Lundstorm 
and Baker (2009) demonstrated that givers, who solely focused on reviewing a peer's writing, tended to gain more than receivers, who only focused on how to use peer's feedback. Givers actively learned how to 'critically self-evaluate' their own writing through offering feedback to peers, and they provided instruction within their own ZPDs.

The current study aims to deepen our understanding of the process of conceptual development of 'stronger learners', that is, learners with more knowledge of the target items than their pair-work partners. We analyze their interactional patterns, the quality of languaging, learning outcomes measured by pre-, post- and delayed post-tests and learners' perceptions of pair-work.

\section{THE CURRENT STUDY}

This study investigates two pairs of learners where one partner initially showed greater knowledge of the target particles than their partner. We specifically examine stronger learners' interaction patterns, levels of engagement, quality of languaging, and perceptions/attitudes toward pair-work, and discuss the possible link to the development of their understanding and use of two Japanese particles, as discussed below.

\section{Japanese particles $n i$ and $d e$}

Like English prepositions in ESL learning, Japanese locative particles, ni/de, shown below ${ }^{2}$, are challenging for JFL learners.

\section{(1) John ga nihon ni iru. NOM Japan LOC is}

John is in Japan.

\section{(2) John ga nihon de hataraite-iru. NOM Japan LOC work-is John is working in Japan.}

In (1), $n i$ indicates the existence/stative location of John while in (2) de indicates where he is working. While English preposition choice depends on the speaker's perception of the Ground ('Japan'), 'a stationary setting relative to a reference frame' in relation to the Figure ('John'), who is 'a moving or conceptually movable entity' (Talmy, 2000: 184), the selection of Japanese $n i$ or de depends on whether the speaker construes the Figure as static or dynamic (Masuda, 2007). When the Figure is construed as static as in (1), $n i$ is selected, and when it is construed as engaged in an activity as in (2), de is selected. Thus, English-speaking L2 learners need to shift their attention to a novel system when choosing the locative particle.

Moreover, polysemy poses another challenge. Both ni/de have locative core meanings and have extended functions (Kabata and Rice, 1997; Moriyama, 2008). The current study deals with four functions of each: $n i$ (stative location, time, goal, purpose) and de (location for event/activity, instrument, range, manner) (see Appendix 2 for examples), all of which, except for manner, had previously been introduced to the students.

In this study, the development of the understanding and use of ni/de particles is assessed by a three-tiered temporal structure of measurement (i.e. pre-, post- and delayed-post-tests). Sato and Ballinger (2016: 7) suggest that using pre/post designs is a desired method for studying peer interaction, but to date, there are very few studies documenting the development of learners' 
This is the version of the article accepted for publication in LANGUAGE AND SOCIOCULTURAL THEORY published by Equinox Publishing: https://doi.org/10.1558/1st.34514

Accepted version downloaded from SOAS Research Online: http://eprints.soas.ac.uk/25615

understanding of complex grammatical concepts in peer interaction by employing a three-tiered temporal structure of measurement (cf. Swain et al., 2009; McDonough, 2004). Notably, when McDonough (2004) used the same tasks in pre-, post-, and 3-week delayed post-test stages, a significant gain was observed only from pre- to post-test, but not from pre- to delayed-post-tests. Thus, when analyzing L2 students' development of abstract concepts, it is essential to assess gains with multiple tasks and with a delayed-post-test.

\section{Research questions}

The study aims to answer the following questions, focusing especially on strong learners:

RQ1 How does individual learners' engagement in pair-work facilitate their learning of the polysemous particles over time?

RQ2 How are attitudes and perception of leaners likely related to their interactional patterns and the quality of languaging?

Using microgenetic analysis, we answer RQ1 by demonstrating how languaging can be linked to learners' improved understanding of the concepts and accurate use of the particles over time. We address RQ2 using a questionnaire and interviews with stimulated recall.

\section{METHOD}

\section{Design}

This study began in the $11^{\text {th }}$ week of the 15 -week semester of a third semester Japanese language course at a U.S. university. The target particles were reviewed in three sessions over one week (Table 1). A total of 17 students initially participated. The pre-test was administered at Time 1. The instructor provided explicit explanation after the pre-test and before two pair-work activities carried out at Time 2. Immediate post-tests were given at the end of Time 2 and at Time 3 . The delayed post-test was administered three weeks after the second immediate post-test at Time 4 .

Table 1: Overview of this study

\begin{tabular}{|c|c|}
\hline Time $1(10 / 27 / 2009)$ & $\begin{array}{l}\text { Pre-tests: fill-in-the-blank test, communicative translation task } \\
\text { Review of the particles given by the instructor }\end{array}$ \\
\hline Time $2(10 / 29 / 2009)$ & $\begin{array}{l}\text { Further review of the particles } \\
\text { Pair-work 1: identifying particle functions }(10 \mathrm{~min}) \text {, immediately } \\
\text { followed by the instructor's feedback } \\
\text { Pair-work 2: reviewing each others' writing }(12 \mathrm{~min}) \\
\text { Immediate post-test: fill-in-the-blank test }\end{array}$ \\
\hline Time $3(11 / 2 / 2009)$ & Immediate post-test: communicative translation task \\
\hline Time $4(11 / 23 / 2009)$ & $\begin{array}{l}\text { Delayed post-tests: fill-in-the-blank test, communicative translation task } \\
\text { Questionnaire } \\
\text { Follow-up interview }\end{array}$ \\
\hline
\end{tabular}


Two tests were designed: (1) a contextualized fill-in-the-blank test where students filled in blanks with particles in four short stories (with 12 blanks in each, making 48 blanks in total, including 16 filler blanks where particles other than ni/de were appropriate), and (2) a communicative translation task where students wrote a message by translating an audio-recorded English voice message into Japanese. Keywords (e.g. Ichiba 'market') were provided so that students could easily mention the target place nouns and particles in their writing. It was designed to elicit 20 particles (10 each of ni/de). Three different versions of the test were prepared for both fill-in-the-blank and writing tests in order to minimize a practice effect.

Before Time 2, all target particles produced in the pre-test translation task were highlighted without indicating whether they were correct or not. The students formed self-selected pairs for two pair-work activities: identifying particle functions used in the sentences on a handout (Pairwork 1) and reading their partner's writing and discussing the use of the particles (Pair-work 2) (e.g. whether or not they would use the particles in the same way and why). It is important to note here that researchers (Swain et al. 2009; Swain and Lapkin 1998, 2002) have pointed out that the languaging of complex concepts can be best accomplished in learners' L1, a procedure followed in our study. The students' exchanges were audio-recorded and transcribed. After the pair-work, the immediate post-test was administered; three weeks later, the delayed post-test, a questionnaire and an interview were administered. ${ }^{3}$

Accuracy rates on student writing were calculated using target-like-use (TLU) analysis (Pica, 1984): the number of target-like instances of the particles divided by the total numbers of obligatory contexts of ni/de and instances of overuse. The two authors independently identified the obligatory contexts in all writings and determined whether a target-like particle was supplied and whether there was any overuse. The inter-rater agreement was $99.0 \%$ for the former, and $99.7 \%$ for the latter. The cases where the raters' coding differed were discussed in order to reach agreement.

The questionnaire was designed to elicit students' perception of the pair-work. Students rated the helpfulness of each pair-work activity to learn nilde on a five-point Likert scale. The questionnaire asked:

1. How helpful was this activity for reviewing $n i$ and $d e$ ?

2. In what ways was this activity helpful or unhelpful?

The stronger learners were also interviewed after the questionnaire. The interviews included a stimulated recall where students were prompted to recall details of the pair-activity, which further helped reveal their attitudes toward the pair-work. Watanabe and Swain (2007: 139) assert that such interviews reveal 'intriguing aspects of what was actually going on in the learners' minds'.

\section{Participants}

Two students' knowledge of the target particles in the fill-in-the-blank pre-test in one of the pairs were similar to the other pair, but differed greatly in the post- and delayed post-tests. These pairs are Alex/Betsy and Dan/Eric (all pseudonyms). Table 2 below shows their scores and gains. All four students, whose first/dominant language was English, started learning Japanese at the same university (see Appendix 1 for their profiles). In each pair, one student (Alex, Dan) achieved higher scores (84\% and $88 \%$ respectively in fill-in-the-blank pre-test) than their peers (both $66 \%$ ) at Time 1 . Thus, we consider Alex and Dan as 'stronger learners'. 
Alex differed greatly from Dan in his learning; only Alex further improved in the delayed post-test. Moreover, his partner, Betsy not only achieved $97 \%$ in the immediate post-test but also improved on the delayed post-test. Note that on the delayed post-test, she left six of the target 30 blanks unfilled, but 21 out of the 24 that she completed were indeed correct (88\%).

Table 2: Student gains

\begin{tabular}{|l|l|l|l|l|l|l|l|l|}
\hline & Fill-in-the-blank & \multicolumn{2}{l|}{ Writing TLU } \\
\hline & Pre-test & Post & Delayed & Gain & Pre-test & Post & Delayed & Gain \\
\hline Alex & 84 & 91 & 94 & +10 & 75 & 89 & 94 \\
& & & & & $9 /(10+2)$ & $8 /(8+1)$ & $15 /(15+1)$ & +19 \\
\hline Betsy & 66 & 97 & $66(88)$ & $+0(+22)$ & 83 & 83 & 90 & +7 \\
& & & & & $10 / 12$ & $10 /(11+1)$ & $9 /(9+1)$ & \\
\hline Dan & 88 & 100 & 78 & -10 & 85 & 77 & 83 & -2 \\
& & & & & $11 / 13$ & $10 / 13$ & $10 / 12$ & \\
\hline Eric & 66 & 94 & 75 & +9 & 38 & 82 & 79 & +41 \\
& & & & & $3 / 8$ & $9 / 11$ & $11 / 14$ & \\
\hline
\end{tabular}

Note:

1. 'Gain' refers to the difference between pre- and delayed-post performances.

2. In cells reporting on writing TLU, 9/(10+2) means that target particles were supplied in nine of 10 obligatory contexts and overused in two non-obligatory contexts.

In the Dan/Eric pair, both showed improvement in the short term, but only Eric, who initially had a lower score, maintained some understanding through the post-test. We identify the students' interactive patterns and engagement levels in an attempt to understand the variable outcomes of these students.

\section{Data Analysis}

Similar to previous studies (cf. Lesser, 2004; Storch, 2002, 2008), the following steps were taken:

1. Each LRE where the participants discussed the target particles was coded as to whether the learners correctly resolved the problem (i.e. reached the correct use of particle). ${ }^{4}$

2. Then, student engagement was classified into two levels, as Elaborate (E) or Limited (L) (Storch, 2008: 100) as defined below.

3. Next we examined each learner's engagement, rather than coding each pair's engagement level (Storch, 2008). The two authors' independent coding of all LREs yielded agreement on $87 \%$ of instances. Those LREs initially coded differently were discussed in order to reach agreement.

Because each learner was coded for engagement level, the pairs' engagement could be any combination of L (Limited) and E (Elaborate) such as L+L, L+E, E+E, L, or E. In E+E, both students participated in elaborate engagement by seeking and providing explanation and/or confirmation. $\mathrm{L}+\mathrm{L}$ refers to the case where one student makes a simple suggestion without 
justification and the other repeats the suggestion. ${ }^{5}$ In cases where one of the learners did not respond to their partner, it was coded as only $\mathrm{L}$ or $\mathrm{E}$, depending on the single learner's engagement. In E, one participant was highly engaged in noticing, explaining, and/or confirming whereas the other showed passive involvement, such as no response, or responding with a phatic utterance (e.g. yeah, ok). L is the case where one student shows limited engagement (e.g. making a suggestion without justification) and the other has neither a response nor a phatic utterance.

\section{RESULTS}

\section{Learner engagement in pair-work}

RQ 1 is answered by identifying the interactional patterns and each learner's engagement in languaging and learning outcomes. Many LREs of Pair-work 1 follow the same pattern of naming the particles' functions after reading the sentence aloud. There are exceptions on a few occasions, which are discussed in the next section.

Students' engagement in Pair-work 2 is summarized in Tables 3 and 4, which indicate whose writing (i.e. particle use) the pair was discussing, and whether particle use was correct or incorrect (incorrect cases in bold). As shown in Table 3, Alex/Betsy had 10 LREs, and consistently resolved the particles correctly and demonstrated collaborative patterns of elaborate engagement (three instances of E+E, 1 E, 6 L). In contrast, Dan/Eric in Table 4 reached correct resolution in five of seven LREs and showed a lack of mutual collaboration (1 instance of $\mathrm{L}+\mathrm{L}, 3$ E, $3 \mathrm{~L})$.

Alex/Betsy pair: Alex's elaborate engagement was observed when reviewing both his own and Betsy's particle use. When Betsy's choice was target-like, Alex showed limited engagement, by agreeing with the choice, which was followed by her phatic utterance, 'ok' (LRE 2-2). When either Betsy or Alex used incorrect particles, elaborate engagement emerged (a total of four instances). Three of these LREs showed collaborative, mutual elaborate engagement. The five cases of such elaborative engagement regarding incorrect usage of nilde with the location functions seem to have contributed to their improved understanding and use of these locative particles with location functions. In delayed-post-test writing, Alex and Betsy consistently used target-like ni/de particles for location. Alex also produced all eight functions of particles (four functions for each of the particles) in the delayed-post writing.

Table 3: LREs and level of engagement by Alex/Betsy

\begin{tabular}{|c|c|c|c|c|c|c|c|}
\hline $\begin{array}{l}\text { LRE } \\
\text { No. }\end{array}$ & Writer & Particle & Function & Accuracy & Alex & Betsy & Pair \\
\hline $2-1$ & \multirow[t]{7}{*}{ Besty } & $n i$ & time, goal* & correct & $\mathrm{L}$ & & $\mathrm{L}$ \\
\hline $2-2$ & & $n i$ & location & incorrect & $\mathrm{L}$ & & $\mathrm{L}$ \\
\hline $2-3$ & & $d e$ & range & correct & $\mathrm{L}$ & & $\mathrm{L}$ \\
\hline $2-4$ & & $d e$ & location & correct & $\mathrm{L}$ & & $\mathrm{L}$ \\
\hline $2-5$ & & $d e$ & location & correct & $\mathrm{L}$ & & $\mathrm{L}$ \\
\hline $2-6$ & & $n i$ & location & incorrect & $\mathrm{E}$ & & $\mathrm{E}$ \\
\hline $2-7$ & & $d e$ & location & incorrect & E & E & $E+E$ \\
\hline
\end{tabular}


This is the version of the article accepted for publication in LANGUAGE AND SOCIOCULTURAL THEORY published by Equinox Publishing: https://doi.org/10.1558/lst.34514

Accepted version downloaded from SOAS Research Online: http://eprints.soas.ac.uk/25615

\begin{tabular}{|c|c|c|c|c|c|c|c|}
\hline $2-8$ & \multirow[t]{3}{*}{ Alex } & $n i$ & time, goal* & correct & & $\mathrm{L}$ & $\mathrm{L}$ \\
\hline $2-9$ & & $n i$ & location & incorrect & E & E & $E+E$ \\
\hline $2-10$ & & $d e$ & location & incorrect & $\mathrm{E}$ & $\mathrm{E}$ & $\mathrm{E}+\mathrm{E}$ \\
\hline
\end{tabular}

* Alex/Betsy talked about the sentence including time $n i$ and goal $n i$.

Table 4: LREs and level of engagement by Dan/Eric

\begin{tabular}{|c|c|c|c|c|c|c|c|}
\hline $\begin{array}{l}\text { LRE } \\
\text { No. }\end{array}$ & Writer & Particle & Function & Accuracy & Dan & Eric & Pair \\
\hline $2-11$ & \multirow[t]{4}{*}{ Eric } & $n i$ & location & incorrect & $\mathrm{L}$ & & $\mathrm{L}$ \\
\hline $2-12$ & & $\begin{array}{l}\text { to } \\
\text { ni }\end{array}$ & $\begin{array}{l}\text { comitative } \\
\text { goal }\end{array}$ & incorrect & $\mathrm{E}$ & & $\mathrm{E}$ \\
\hline $2-13$ & & $n i$ & location & incorrect & $\mathrm{L}$ & $\mathrm{L}$ & $\mathrm{L}+\mathrm{L}$ \\
\hline $2-14$ & & $n i$ & location & incorrect & $\mathrm{L}$ & & $\mathrm{L}$ \\
\hline $2-15$ & \multirow[t]{3}{*}{ Dan } & $d e$ & location & incorrect & & $\mathrm{E}$ & $\mathrm{E}$ \\
\hline $2-16$ & & de & location & incorrect & & $\mathrm{E}$ & $\mathrm{E}$ \\
\hline $2-17$ & & $d e$ & location & correct & $\mathrm{L}$ & & $\mathrm{L}$ \\
\hline
\end{tabular}

Dan/Eric pair: In contrast to Alex/Betsy, Dan/Eric showed no collaborative pattern of elaborate engagement. Dan exhibited some limited engagement when the pair was considering both Eric's and Dan's particle. Note that Dan's one instance of elaborate engagement in LRE 212 was non-collaborative, as will be discussed later. Eric had two instances of elaborate engagement when reviewing Dan's writing, but his elaborate engagement was not collaborative, showing a dominant-passive pattern. Five cases related to incorrect $n i / d e$ location $(1 \mathrm{~L}+\mathrm{L}, 2 \mathrm{~L}, 2$ E) appear to have positively influenced Eric, who made three ni/de locative errors in pre-test writing but none in the delayed post-test. Contrarily, Dan consistently made errors of locative ni/de in all three of his writings even though he made fewer errors overall than Eric.

\section{Languaging of Alex and Betsy}

During Pair-work 1, Alex mostly took the lead and Betsy followed by collaboratively engaging in joint-search for particle meanings. When Betsy suggested a de function in line 2 (LRE 1-1), Alex did not immediately agree with her. However, when she justified her choice with translation, he acknowledged with 'yeah,' and accepted her choice (line 5). The languaging sequence is presented below with English glosses of the Japanese indicated in parentheses.

LRE 1-1: Alex/Betsy in Pair-work 1
$1 \mathrm{~A}$ : Oh, yeah, hikooki-de
aimashita. Hum...

$2 \mathrm{~B}: \quad$ location?

(airplane-LOC met)

$3 \mathrm{~A}$ : $\quad$ er $==$

$4 \mathrm{~B}$ : on the plane, meeting.

$5 \mathrm{~A}$ : Yeah, you're absolutely right.

Next consider LRE 1-2. 
This is the version of the article accepted for publication in LANGUAGE AND SOCIOCULTURAL THEORY

published by Equinox Publishing: https://doi.org/10.1558/lst.34514

Accepted version downloaded from SOAS Research Online: http://eprints.soas.ac.uk/25615

LRE 1-2: Alex's monologue in Pair-work 1

$1 \mathrm{~A}: \quad k y o o t o-d e$ mimashita...I want to say 'state'?

(Kyoto-LOC saw)

Oh, wait, now, where you saw it?

So, that would be location for an action.

Alex's initial preference was 'state' (stative locative) (line 1), but he immediately realized that it was incorrect. Providing the reason for $d e$, he successfully named the correct function without his peer's help. These utterances in LRE 1-2 occurred a few minutes after LRE 1-1, demonstrating Alex's capacity to internalize the new concept and self-regulate by handling the mental activity under his voluntary control. In a Vygotskian framework, self-regulation occurs when one regulates mental activity in private speech, while other-regulation, often, though not always, occurs through social speech. When other-regulation appears first on the interpsychological plane, self-regulation may occur next on the intrapsychological plane.

Based on Vygotsky's concept that social speech is a source of thinking, Gal'perin (1969) proposes two types of verbal actions - what Haenen (2001: 163) calls communicated thinking ${ }^{6}$ and dialogical thinking. In the former, learners perform a verbal action while making it comprehensible not only to themselves but also others in overt or social speech. In the latter, learners directs covert speech to themselves, rather than others. Alex's shift of verbal actions from LRE 1-1 to LRE 1-2 is an example of a potential transformation from communicated thinking to "external speech to oneself" (Gal'perin 1989: 53) or toward dialogical thinking, and it allowed Alex to engage in the internalization of the concept, and begin self-regulating his behavior (Haenen 2001:164). Microgenetic analysis allows us to see that Alex's interaction with Betsy was indeed an effective learning opportunity for him (the origin), letting him resolve the task himself (the process of learning).

Ten LREs were identified during Alex/Betsy's Pair-work 2. When the target particle was incorrect, all LREs were elaborate (3 instances of E+E, $1 \mathrm{E}$ ) except for one case. Consider one $\mathrm{E}+\mathrm{E}$ case below.

LRE 2-9: Betsy reading Alex's writing (E+E)

$1 \mathrm{~B}$ : What is the third line below? What's going on here?

2 A: here? $\begin{array}{ll}\begin{array}{l}\text { sono ato } \\ \text { (thatafter }\end{array} & \begin{array}{l}\text { Bobu-ni ita hoteru-ni ... ah, } \\ \text { Bob-to was hotel-LOC) }\end{array}\end{array}$

$\begin{array}{llr}\text { hura dansu-no } & \text { paatii-ga } & \text { arimashita. } \\ \text { (fura dance-GEN } & \text { party-NOM } & \text { there was) }\end{array}$

after that. The hotel that Bob stayed at is where the fura party was, so, I guess it should be de, wait that make sense to you? like after what happened here, which is that noun modifying clause, Bobu-ni ita hoteru The hotel that Bob stayed at is where.

(Bob-to was hotel)

$3 \mathrm{~B}$ : You got that grammar structure here wrong. You can't do that for anything!

4 A: I think that should be de. yeah, now I see what's going on

(laughter)....all right.

5 B: Yeah.

Betsy initiated a correction: 'what's going on here?' (line 1). Importantly, her utterance triggered Alex's recognition of his error. Betsy's action represents 'an interactive means of initiating a 
focus on language' (Storch, 2001: 42), which naturally led to a smooth dialogue, free from an attitude of domination. Alex confirmed which sentence was in question (line 2). Through reading his own writing aloud and providing a translation, he realized that his first choice was incorrect. He thereupon engaged in correction and asked for Betsy's confirmation. Alex provided both a reason for his new choice and further justification regarding the structure. After Betsy evaluated Alex's choice (line 3), Alex reconfirmed his choice, and verbalized his full understanding, with Betsy echoing agreement of Alex's rationale. Such evaluative comments in languaging are found to facilitate learning (Swain et al., 2009). This confirms Ohta's (1995: 117) finding that a stronger learner's collaborative interaction allows peers to act as both an expert/novice and to give them more opportunities to apply their developing knowledge to their own language development.

LRE 2-2 below shows a single instance of L-type elaboration for incorrect use. Alex initiated a correction while looking at Betsy's writing, but Alex's turn was rather short, as he merely provided the target particle after reading aloud (lines 1-2). Coding of the interaction is as follows: the engagement level and engaging student's name are indicated in parenthesis at the end of the first line: L [Alex].

LRE 2-2: Alex reading Betsy's writing. L [Alex]

$1 \mathrm{~A}: \quad$ Er. Hanauma-bei-ni daibingu-o shimashita. This might be de.

2 B: Yeah.

(Bay-LOC diving-ACC did)

In a different instance, however, Alex's last correction of Betsy's writing generated more engagements, as shown below.

LRE 2-7: Alex reading Betsy's writing (E+E)

1 A: hoteru-de Mearii-to Utada Hikaru-no konsaato-ni ikimashita.

(Hotel-LOC Mary-with singer's name-GEN concert-GAL went)

$a=$ since this is a place where you are going to, I wanna say...

I wanna say this should be ni, but I could be wrong.

2 B: Yeah...na..ok.

$3 \mathrm{~A}:$ I'm not sure.

$4 \mathrm{~B}$ : because there is a concert at the hotel.

$5 \mathrm{~A}$ : right.

$6 \mathrm{~B}: \quad$ In that sense, that should be $d e \ldots$

$7 \mathrm{~A}$ : yeah.

$8 \mathrm{~B}:$...going to the hotel.... That would be ni, right?

$9 \mathrm{~A}$ : Yeah,yeah. I think if you broke up and say 'hoteru-de utada

(Hotel-LOC

hikaru-no konsaato-ga arimasu'.

concert-NOM there is)

$10 \mathrm{~B}:$ hum..

$11 \mathrm{~A}$ : Then, soko-ni ikimashita, or something like that.

12 B: Yeah. (there-GAL went)

After reading Betsy's writing aloud, Alex pointed out that 'hotel' is a place to go to, and made a suggestion on her particle choice in a mitigated way, 'I wanna say this should be ni, but I could 
be wrong'. Betsy briefly acknowledged this (line 2), but Alex was still not completely sure, stating 'I'm not sure'. This seems to be an example of 'the moment of awareness' which originates on the social plane (Ganem-Gutiérrez, 2008:130), an instance when the learners realize a lack of linguistic knowledge, or in this case a lack of confidence, during collaboration. Their collaborative correction continued as Betsy started to explain why she used de (lines 4 and 6), which was followed by Alex's acknowledgements, 'right' and 'yeah'. Through this languaging, Betsy seems to become aware that $n i$ should mark the destination (line 8), and then Alex's new suggestion (lines 9,11) and Betsy's confirmation (line 12) wraps up this LRE.

This lengthy stretch of languaging clearly demonstrates that the Alex/Betsy pair actively and equally contributed to the improved understanding of particles. This pair exhibits a collaborative relationship (Storch, 2002). This collaborative interaction likely led both of them to a deeper conceptual knowledge of the challenging particles ni/de, which probably resulted in long-lasting gains, especially for Alex, as shown in the three-week-delayed post-test. Significantly, initiation of correction was evenly distributed in this pair and the response was always collaborative throughout their pair-work.

\section{Languaging of Dan and Eric}

In contrast, the Dan/Eric pair did not seem to work collaboratively. They simply limited themselves to a type of routine to complete the task, without exchanging their thoughts about particle use, thus minimizing languaging. Consider LRE 1-3.

LRE 1-3: Dan/Eric in Pair-work 1 [L + L]

$1 \mathrm{E}:$ kazoku-ni ai-ni ikimasu.

(family-DAT meet-to go)

$2 \mathrm{D}$ : this is a direction.

--- 6-second pause--

gohan-o tabe-nikaerimasu.

(rice-ACC eat-to return)

$3 \mathrm{E}:$ direction, as well.

$4 \mathrm{D}$ : Isn't that purpose?

$5 \mathrm{E}$ : tabe-ni...yeah. That's the fourth one: location, goal, time and purpose?

6 D: Yeah. koohii-o kai-ni ikimasu. That's alsopurpose. (coffee-ACC buy-to go)

I think $A$ is also purpose.

When Eric read a sentence aloud, Dan incorrectly named the function (line 2). There was a long pause during which Eric neither acknowledged nor disagreed with Dan. Dan continued and read the next sentence. Hearing Eric's incorrect naming of the function, Dan tried to correct it (line 4). Eric started to reread the target phrase and immediately accepted Dan's suggestion, saying 'yeah'. Then, without attempting to explain why Dan's new choice was correct, Eric simply read the list of all functions given on a previously distributed handout (line 5). Finally, Dan acknowledged the correction, and moved to the next sentence, where he named the function correctly.

Seven LREs were identified during Dan/Eric's Pair-work 2. Out of six cases where incorrect particles were noticed, no LRE was deemed E+E. This pair did not seem to interact 
collaboratively and often skipped stages of noticing, evaluating, reasoning, or confirming. For instance, in LRE 2-11, in response to Eric's writing, biichi-ga ichiba arimasu (beach-NOM market exist, intended: 'there is a farmer's market on the beach') where $g a$ was misplaced and $n i$ was missing, Dan first checked the meaning of the word, ichiba.

LRE 2-11: Dan is reading Eric's writing, L [Dan]

$1 \mathrm{D}:$ What's ichiba?

$2 \mathrm{E}:$ It's a farmer's market.

3 D: biichi-ga ichiba-ni arimasu.

(beach-NOM market-LOC there is)

After hearing Eric's answer, Dan supplied a sequence containing the misplaced particles biichiga ichiba-ni arimasu ('there is beach in the market') without justification, leaving no room for negotiation for Eric. The sequence was still incorrect, which was not noticed by Eric. It is hard to gauge if Eric's silence after Dan's utterance meant that Eric accepted Dan's feedback or not.

In LRE 2-12, Dan continues reading Eric's writing, Hawai-to imooto-ni ikimasu, where he misused a particle to (comitative) in place of $n i$, and also misused $n i$ (goal) after imooto 'young sister' in place of to.

LRE 2-12: Dan checking Eric's writing, E [Dan]

$1 \mathrm{D}$ : This one should be 'imooto-to

(younger sister-with Hawaii-GAL go)

$2 \mathrm{E}: \mathrm{OK}$.

Hawai-ni ikimasu'.

$3 \mathrm{D}$ : ni direction? I don't know... imooto-wa...

$4 \mathrm{E}$ : Do the one I did wrong.

(younger sister-TOP)

Dan initiated correction assertively stating, 'This should be...' and Eric immediately acknowledged it, stating 'OK'. Dan then named the ni function, 'direction' (line 3), less assertively, uttering 'I don't know...' Using a directive is one feature of non-collaborative pairwork (Storch 2001: 45). In other words, though Dan's engagement is 'elaborate' in a sense that he tried to explain the choice of $n i$ by naming the function, it is not a collaborative type of engagement. Note that he used a directive again in subsequent LRE after LRE 2-12, 'you should say....'. Dan's directives and Eric's less involved remark (line 4) indicate the non-collaborative and non-interactive nature of their pair-work.

Next, in LRE 2-15, Eric also failed to correct Dan's mistakes in his writing.

LRE 2-15: Eric checking Dan's writing, E [Eric]

$1 \mathrm{E}$ : You had two that was wrong. The first one, eight. [the $8^{\text {th }}$ line]

Biggu-airando-de takusan hito-ga arimasu,

(Big island-LOC many person-NOM there is)

That's... I think it should be $n i$, right? It's location.

$2 \mathrm{D}$ : I had a lot of trouble, yeah.

$3 \mathrm{E}$ : which is the same as your last one. [referring to the last particle used in Dan's writing]

Eric pointed out Dan's error by declaring 'you had two that was [sic] wrong.' (line 1). After reading Dan's writing, Eric corrected the particle de to $n i$ 'location' without getting attention from Dan. As Storch (2002) points out, those who have limited engagement rarely draw the 
partner's attention to the problem. Dan immediately accepted his correction saying 'I had a lot of trouble, yeah,' followed by Eric's comment about Dan's similar mistake. Eric read that similarly mistaken sentence aloud in lines 1 (LRE 2-16).

LRE 2-16: immediately after LRE 2-15, E [Eric]

$1 \mathrm{E}:$ biichi-de ichiba-ga arimasu (Beach-LOC market-NOM there is)

2 D: [laughter] I just really had one. I got wrong.

$3 \mathrm{E}$ : Which should be ni, location.

4 D: Yeah.

Dan laughed and admitted his error (line 2). Eric provided the correct particle and named the function, which Dan acknowledged. Rather than collaborating by negotiating ZPDs or consolidating knowledge, this pair focused on fixing particles.

\section{Perception of the pair-work}

We now examine the students' responses to the questionnaire and stimulated recall interviews to address RQ2. All four students rated the helpfulness of the pair-work activities on a five-point Likert scale, and explained how they were helpful. Our focal participants, Alex and Dan, (stronger learners) participated in interviews. Pair-work 1 was rated as five ('very helpful') by both Alex and Dan with reasons like 'another person's thoughts' (Alex) and 'working with a partner helped for ones I was unsure about' (Dan). Betsy's rating was four ('helpful'), with a statement, 'I feel like I remember it better if I can discuss it with a friend'. Her answer implies that she has benefited from verbal actions in two ways, both communicated thinking and dialogic thinking. Eric's rating was three ('somewhat helpful'), commenting on 'another perspective'. Pair-work 2 was rated by Alex, Betsy and Eric as five, acknowledging the benefit of working in pairs for reviewing particles in their writing. Dan rated it as four, stating 'It helped practice using particles in real speech rather than just an example'.

While the questionnaire shows similarly positive perceptions, the interviews by Alex and Dan elucidated their differing perceptions and attitudes, as shown below.

Alex: $\quad$...If I'm working with someone else, then I give him my idea, and my idea might be incorrect then that can make me reassess how I thought about it. Then, hopefully we can get right answers.

Interviewer: So, through the interaction with your partner, Betsy?

Alex: $\quad$ Right.

Interviewer: You get more thoughts?

Alex: $\quad$ Right. Man, because I don't restrict to what I think is right, because I could be wrong, you know.

Alex's utterances here also exemplify that he has benefited from communicated thinking, which supports his self-regulation. Alex's positive attitude toward pair-work was likely to have led him to more instances of elaborate engagement in pair-work when both giving and receiving feedback, and his high level of attainment of understanding. This also concurs with Storch (2005, 2008), who states that learners who exhibited 'higher engagement' and 'positive affects toward his partner' did retain the knowledge they gained. 
This is the version of the article accepted for publication in LANGUAGE AND SOCIOCULTURAL THEORY published by Equinox Publishing: https://doi.org/10.1558/lst.34514

Accepted version downloaded from SOAS Research Online: http://eprints.soas.ac.uk/25615

Dan, whose engagement in languaging was limited, stated, 'I think we got what we need to know out of the exercise' and 'the thing is that we pretty much knew the stuff', as shown below.

(After listening to their recorded languaging, LRE 2-12)

Interviewer: Eric said 'Do the one I did wrong.'

Dan: [laughter]

Interviewer: and you didn't explain much and you just pointed out.

Dan: [laughter]

Interviewer: I want to know why...I mean, you just thought that there is no need to explain or you wanted him to explain?

Dan: $\quad$ I mean, I think we got what we need to know out of the exercise, I mean.

Interviewer: hum...

Dan: $\quad$ The thing is that we pretty much knew the stuff, because like, we are in the second page, we are kind of rush to write, you know.

Because Dan's perceived responsibility was just to find and fix his partner's mistakes, and because his assumption was that his pair was mostly correct, he failed to engage in languaging. This is despite the fact that he was sometimes unsure about particles and received help from Eric (LREs 2-15 and 2-16). Dan's attitude may have affected Eric's attitude, as shown in Eric's utterance 'do what I did wrong.', which might have been in response to, or as resistance against, Dan's dominance. This non-reciprocal limited engagement may account for the fact that they did not gain much, in contrast to the other pair (Storch, 2005, 2008).

\section{SUMMARY AND CONCLUSION}

Through a close examination of learner engagement in languaging and a microgenetic analysis, this study demonstrated that both interaction patterns and quality of engagement affect the internalization of the conceptual features of Japanese particles ni/de as assessed at three points in time. The Alex/Betsy pair showed reciprocal elaborate engagement in collaborative patterns (cf. Storch 2001, 2002, 2008). Alex, the stronger peer, evidently further improved his understanding, which led to longer-term retention. He actively engaged in languaging (e.g. providing justification), co-constructed meanings, and increased the learning opportunity for 'the moment of awareness' when both giving and receiving feedback, which may have helped him internalize the new concepts and regulate his mental activities. In contrast, the Dan/Eric pair demonstrated only non-reciprocal limited engagement in dominant-passive interaction most of the time. In their minimal languaging, even instances of elaborate engagement were not collaborative. Though Eric showed notable improvement, possibly due to his low scores at the beginning, Dan, the stronger peer both before and after the tests, did not show any development over time.

The students' perceptions and attitudes toward pair-work seem to explain their variable degrees of engagement in LREs, and likely influenced their learning outcomes. Alex highly rated the helpfulness of the activity and expressed a positive attitude in the interview, using the phrase 'get more thoughts'. Dan's goal in the pair-work was merely to get the work done (indicated by his perceived responsibility of finding his partner's errors), hardly drawing attention from his peer or creating a ZPD for his partner or himself, and showing a dominant attitude characterized by his frequent use of the directive 'you should.../it should ...' (Storch, 2001). In short, Dan did not make an effort to engage in much languaging. This underscores the importance of uncovering learners' perceptions and attitudes through such procedures as questionnaires and 
interviews with stimulated recalls, which only then facilitate the researchers' accurate assessment of the efficacy of the pair-work. The microgenetic analysis presented here deepens our understanding of pair-work dynamics. The impact of languaging in collaborative interaction seems to be immense for L2 learning, highlighting a closer relationship between engagement levels, learning gains, and student perceptions and attitudes.

In sum, our findings substantiate research by Storch $(2001,2002,2008)$ and Watanabe and Swain $(2007,2008)$, demonstrating that a collaborative orientation during pair-work is conducive to L2 learning. We found that collaborative orientation helped the stronger learner with a positive attitude to consolidate and internalize the conceptual knowledge of challenging particles, which was mediated by a peer, and led to target-like use over time. When the pair-work has a collaborative orientation, communicated thinking is more likely to lead to dialogical thinking. Our findings also echo work by Storch $(2004,2005)$ and Kim and McDonough (2008) that focuses on the importance of examining students' perceptions toward pair-work.

Awareness of the benefits of active and collaborative involvement in languaging may be a prerequisite for pairs to achieve a long-lasting understanding of challenging items, and essential for effective communicative classroom instruction. To raise such awareness and to enhance interactional patterns, it is crucial for instructors to guide learners to engage in languaging collaboratively and privately. We suggest that we prepare students to engage in collaborative languaging prior to pair-work. With regard to how to guide students to shift their orientation to collaboration, work by Kim and McDonough (2011) is informative. They found that showing video-recorded model of collaborative learning enabled adolescent students learning English to be more collaborative. Replication studies of the effectiveness of such pretask modeling in other teaching contexts, as well as exploration of other procedures for this purpose, are desired for further understanding and for improved practice.

Future studies would also be advised to incorporate both pre-test and post-test attitudinal questionnaires and interviews in order to account for the sources of differences in languaging, and to assess the relative efficacy of explicit instruction and pair-work separately and in combination. Furthermore, a greater number of pairs should be evaluated to substantiate the effects of languaging on conceptual learning in collaborative interactions.

\section{Acknowledgments}

We express our sincere gratitude for the anonymous reviewers who provided us helpful comments. We are also extremely grateful to the journal editor, Professor James Lantolf, for giving us valuable suggestions and information.

\section{Notes}

1. See Vygotsky (1978: 86) for the original definition of the ZPD.

2. The abbreviations used in this article are as follows: NOM: nominative [ $\mathrm{g} a]$, ACC: accusative [o], DAT: dative [ni], GEN: genitive [no], LOC: locative [ni, de], GAL: goal [ni], TIM: time [ni], PUR: purpose [ni], INS, instrumental [de], MAN: manner [ni], TOP: topic [wa]. The transcription codes used are as follows: , slight rise in intonation; . falling intonation; ? appeal; = elongation of a syllable; ... long pause; .. short pause

3. Learning occurred due to both the instructor's review and the pair-work; however, it should be emphasized that it is each pair's pair-work that has led to the differential learning.

4. Since the focus of the present study is on particles, LREs related to other aspects such as spelling are not analysed. 
This is the version of the article accepted for publication in LANGUAGE AND SOCIOCULTURAL THEORY published by Equinox Publishing: https://doi.org/10.1558/lst.34514

Accepted version downloaded from SOAS Research Online: http://eprints.soas.ac.uk/25615

5. See Excerpt 3 in Storch (2008: 102) for an example.

6. See Arievitch and Haenen (2005: 158) who refer to overt speech as communicative thinking, instead of communicated thinking.

\section{About the authors}

Kyoko Masuda is Associate Professor in the School of Modern Languages at the Georgia Institute of Technology, USA. She received her Ph.D from the University of Arizona. Her current research areas include cognitive linguistics, sociocultural theory, second language acquisition, Japanese discourse. Her recent work include Cognitive Linguistics and Sociocultural Theory: Applications to Language Teaching (Mouton de Gruyter) co-edited with Carlee Arnett and Angela Labarca, and her second edited volume, Cognitive Linguistics and Japanese Pedagogy: A Usage-based Approach to Language Learning and Instruction (Mouton de Gruyter).

Noriko Iwasaki is Senior Lecturer of Language Pedagogy in the Department of Linguistics, SOAS University of London. She completed her Ph.D at the University of Arizona. Her research interests include sentence production processes, second language acquisition (grammar, pragmatics, use of mimetics, study abroad), and language pedagogy. Her recent work includes The Routledge Intermediate-Advanced Japanese Reader: A Genre-based Approach to Reading as a Social Practice, co-authored with Yuri Kumagai and edited volume, The Grammar of Japanese Mimetics: Perspectives from Structure, Acquisition and Translation (Routledge), coedited with Peter Sells and Kimi Akita.

\section{References}

Arievitch, I. and Hansen, J. (2005). Connecting sociocultural theory and educational practice: Galperin's approach. Educational Psychologist 40 (3), 155165.

Aljaafreh, A. and Lantolf, J. (1994). Negative feedback as regulation and second language learning in the zone of proximal development. The Modern Language Journal 78 (4), 465483.

Buescher, K. and Strauss, S. (2015). A cognitive linguistic analysis of French prepositions à, dans, and en and a sociocultural theoretical approach to teaching them. In K. Masuda, C. Arnett \& A. Labarca (eds.), Cognitive Linguistics and Sociocultural Theory: Applications for Second Foreign Language Teaching 155181. Boston and Berlin: Mouton de Gruyter.

Gal'perin, P. Y. (1969). Stage in the development of mental acts. In M. Cole and I. Maltzman (eds.) A handbook of contemporary Soviet psychology 249272. New York: Basic Books

Gal'perin, P. Y. (1989). Mental actions as a basis for the formation of thoughts and images. Soviet Psychology 27 (2), 4564.

Ganem-Gutiérrez, A. (2008). Microgenesis, method and object: A study of collaborative activity in a Spanish as a foreign language classroom. Applied Linguistics 29/1: 120148.

Haenen, J. (2001). Outlining the teaching-learning process: Piotr Gal'perin's contributioin. Learning and Instruction 11, 157170.

Iwasaki, N. (2002). Simple performance-oriented test (SPOT) vs. oral proficiency interview (OPI). Journal of Japanese Language Teaching 114, 100105. 
This is the version of the article accepted for publication in LANGUAGE AND SOCIOCULTURAL THEORY published by Equinox Publishing: https://doi.org/10.1558/lst.34514

Accepted version downloaded from SOAS Research Online: http://eprints.soas.ac.uk/25615

Kabata, K. and Rice, S. (1997). Japanese ni: The particulars of a somewhat contradictory particle. In M. Verspoor, K. Lee and E. Sweetser (eds.) Lexical and Syntactical Constructions and the Construction of Meaning 109127. Amsterdam and Philadelphia: John Benjamins.

Kim, Y. and McDonough, K. (2008). The effect of interlocutor proficiency on the collaborative dialogue between Korean as a second language learners. Language Teaching Research 12 (2), 211234.

Kim, Y. and McDonough, K. (2011). Using pretask modelling to encourage collaborative learning opportunities. Language Teaching Research 15 (2), 183199.

Lantolf, J. P. (2000). Sociocultural Theory and Second Language Learning. Oxford University Press.

Leeser, M. (2004). Learner proficiency and focus on form during collaborative dialogue. Language Teaching Research 8 (1), 5581.

Lundstrom, K. and Baker, W. (2009). To give is better than to receive: The benefits of peer review to the reviewer's own writing. Journal of Second Language Writing 18: 3043.

Masuda, K. (2007). Japanese postpositions $n i$ and $d e$ : cognitive linguistic approach. Chicago Linguistic Society 39, 1425.

Masuda, K and Labarca, A. (2015). Schemata use and languaging quality in learning Japanese polysemous particlels $n i$ and $d e "$. In K. Masuda, C. Arnett \& A. Labarca (eds.), Cognitive Linguistics and Sociocultural Theory: Applications to Foreign/Second Language Teaching 203232. Boston and Berlin: Mouton de Gruyter.

McDonough, K. (2004). Learner-learner interaction during pair and small group activities in a Thai EFL context. System 32 (2), 207224.

Nassaji, H., and Swain, M. (2000). A Vygotskian perspective on corrective feedback in L2: The effect of random versus negotiated help on the learning of English articles. Language Awareness 9, 3451.

Moriyama, S. (2008). Ninchigengogaku kara Mita Nihongo Kakujyoshi no Imikoozoo to Shuutoku. [A cognitive linguistic view of Japanese case particles: Their semantic constructions and acquisition for teaching Japanese]. Tokyo: Histuzi Syobo.

Negueruela, E. and Lantolf, J. (2006). Concept-based instruction: Teaching grammar in an intermediate-advanced Spanish L2 university classroom. In R. Salaberry and B. Lafford (eds.) The Art of Teaching Spanish: Second Language Acquisition from Research to Praxis 79102. Georgetown: Georgetown University Press.

Ohta, A. (1995). Applying sociocultural theory to an analysis of learner discourse: Learnerlearner collaborative interaction in the zone of proximal development. Issue in Applied Linguistics 6 (2), 93121.

Ohta, A. (2001). Second Language Acquisition Processes in the Classroom: Learning Japanese. Mahwah, NJ: Lawrence Erlbaum Association Publisher.

Philp, J., Walter, S. and Basturkmen, H. (2010). Peer interaction in the foreign language classroom: what factors foster a focus on form? Language Awareness 19 (4), 261279.

Philp, J., Adams, R. and Iwashita, N. (2014). Peer Interaction and Second Language Learning. London and New York: Routledge.

Pica, T. (1984). Methods of morpheme quantification: their effect on the interpretation of second language data. Studies in Second Language Acquisition 6 (1), 6978.

Sato, M. and Ballinger, S. (eds.) (2016). Understanding Peer Interaction, Research Synthesis and Directions. Amsterdam \& Philadelphia: John Benjamins. 
This is the version of the article accepted for publication in LANGUAGE AND SOCIOCULTURAL THEORY published by Equinox Publishing: https://doi.org/10.1558/lst.34514

Accepted version downloaded from SOAS Research Online: http://eprints.soas.ac.uk/25615

Sakoda, K. (2001). Gakushuusha no bunpoo shori [Learners' grammar strategies: Learners look at nearby contexts].. In H, Noda, K. Sakoda, M. Shibuya and N. Kobayashi (eds.), Nihongo Gakushuusha no Bumpoo Shuutoku [Acquisition of grammar by learners of Japanese]. Tokyo: Taishuukan Shoten.

Storch, N. (1999). Are two heads better than one? Pair work and grammatical accuracy. System 27 (3), 363374.

Storch, N. (2001). How collaborative is pair work? ESL tertiary students composing in pairs. Language Teaching Research 5 (1), 2953.

Storch, N. (2002). Patterns of interaction in ESL pair work. Language Learning 52 (1), 119158.

Storch, N. (2004). Using activity theory to explain differences in patterns of dyadic interactions in an ESL class. The Canadian Modern Language Review. 60 (4), 457480.

Storch, N. (2005). Collaborative writing: product, process and students' reflections. Journal of Second Language Writing 14, 153173.

Storch, N. (2008). Metatalk in a pair work activity: Level of engagement and implications for language development. Language Awareness 17 (2), 361392.

Storch, N. (2013). Collaborative Writing in L2 Classroom. Bristol: Multilingual Matters.

Storch, N. and Aldosari, A. (2012). Paring learners in pair work activity. Language Teaching Research 17 (1), 3148.

Suzuki, W. (2016). The effect of quality of written languaging on second language learning. Writing and Pedagogy 8 (3), 461482.

Swain, M. (2000). The output hypothesis: Theory and research. In Lantolf J. (ed.): Sociocultural Theory and Second Language Learning. Oxford: Oxford University Press.

Swain, M. (2006). Languaging, agency and collaboration in advanced language proficiency. In Byrnes, H. (ed.): Advanced Language Learning: The Contribution of Halliday and Vygotsky 95108 London: Continuum.

Swain, M. and Lapkin, S. (1998). Interaction and second language learning: Two adolescent French immersion students working together. Modern Language Journal 82 (3), 320337.

Swain, M. and Lapkin, S. (2002). Talking it through: two French immersion learners' response to reformulation. International Journal of Educational Research 37 (3-4), 285304.

Swain, M., Lapkin, S., Knouzi, I., Suzuki, W. and Brooks, L. (2009). Languaging: University students learn the grammatical concept of voice in French. The Modern Language Journal 93 (1), 529.

Talmy, L. (2000). Toward a Cognitive Semantics, vol. 2. MIT: MIT Press.

Watanabe, Y. and Swain, M. (2007). Effects of proficiency differences and patterns of pair interaction on second language learning: collaborative dialogues between adult ESL learners. Language Teaching Research 11 (2), 121142.

Watanabe, Y. and Swain, M. (2008). Perception of learner proficiency: Its impact on the interaction between an ESL learner and her higher and lower proficiency partners. Language Awareness 17 (2), 115130.

Wertsch, J.V. (1985). Vygotsky and the Social Formation of Mind. Cambridge,MA: Harvard University Press.

Vygotsky, L. S. (1978). Mind in Society. Cambridge, MA: Harvard University Press. 
This is the version of the article accepted for publication in LANGUAGE AND SOCIOCULTURAL THEORY published by Equinox Publishing: https://doi.org/10.1558/1st.34514

Accepted version downloaded from SOAS Research Online: http://eprints.soas.ac.uk/25615

Appendix 1: Participants profiles

\begin{tabular}{|l|l|l|l|l|}
\hline & Heritage and language spoken at home & Major & $\begin{array}{l}\text { Languages } \\
\text { Studied }\end{array}$ & SPOT score* \\
\hline Alex & African American, English & $\begin{array}{l}\text { Computer } \\
\text { Science }\end{array}$ & $\begin{array}{l}\text { Spanish } \\
\text { French }\end{array}$ & 37 \\
\hline Betsy & European American, English & Management & Latin & 30 \\
\hline Dan & $\begin{array}{l}\text { Chinese American, } \\
\text { English and Mandarin Chinese }\end{array}$ & Engineering & None & 27 \\
\hline Eric & $\begin{array}{l}\text { Japanese American (His father is } \\
\text { Japanese), only English }\end{array}$ & Engineering & None & 24 \\
\hline
\end{tabular}

*The four students took SPOT (Simple Performance-Oriented Test) version B at the beginning of the semester. The SPOT scores correlate with oral proficiency interview (OPI) scores of American Council on the Teaching of Foreign Languages (ACTFL) (Iwasaki, 2002). The four students were approximately novice-high on the ACTFL OPI scale.

Appendix 2: The particle functions ni/de tested in this study

\begin{tabular}{|l|l|}
\hline Functions & Examples \\
\hline Stative Location & $\begin{array}{l}\text { Resutoran-ni piano-ga aru. } \\
\text { Restaurant-LOC piano-NOM there is } \\
\text { There is a piano in the restaurant. }\end{array}$ \\
\hline Time & $\begin{array}{l}9 \text { ji-ni } \\
9 \text { o'clock-TIM class-NOM begin } \\
\text { The class begins at 9 o'clock. }\end{array}$ \\
\hline Destination & $\begin{array}{l}\text { Toshokan-ni iku. } \\
\text { Library-GAL go } \\
\text { I go to the library. }\end{array}$ \\
\hline Purpose & $\begin{array}{l}\text { hirugohan-o tebe-ni kaeru. } \\
\text { Lunch-ACC eat-PUR go home } \\
\text { I go home to eat lunch. }\end{array}$ \\
\hline Location for event/activity & $\begin{array}{l}\text { Resutoran-de paatii-ga aru. } \\
\text { Restaurant-LOC party-NOM these is } \\
\text { There is a concert in the restaurant. }\end{array}$ \\
\hline Instrument & $\begin{array}{l}\text { Hashi-de gohan-o taberu. } \\
\text { Chopsticks-INS rice-ACC eat } \\
\text { I eat rice with chopsticks. }\end{array}$ \\
\hline Range & $\begin{array}{l}\text { Fuji san-wa nihon-de ichiban takai. } \\
\text { Mt. Fuji-TOP Japan-RAN most high } \\
\text { Mt. Fuji is the highest in Japan. }\end{array}$ \\
\hline Manner & $\begin{array}{l}\text { Akaidoresu-de odoru. } \\
\text { Red dress-MAN dance } \\
\text { Idance in a red dress. }\end{array}$ \\
\hline
\end{tabular}

